\title{
Effects of smoking on oral cancer transcriptome
}

Type: Meeting Abstract

Abstract:

Introduction: Oral cancer is a debilitating disease and the survival rates for these patients have not improved over the past decades. Tobacco smoking is one of the most common risk factor associated with oral cancer. Objectives: To explore and identify differential genes expression associated with tobacco smoking. Methodology: Next generation sequencing using the Illumina Genome Analyzer was done to sequence five fresh frozen oral cancer tissue samples from smoking patients, two of which were former smoker and an additional 8 samples consisting of normal oral mucosal tissues from the alveolar mucosa of non-cancer patients where 4 were smokers and another 4 were non-smokers. The tissues and socio- demographic information were obtained from the Malaysian Oral Cancer Data and Tumour Bank System (MOCDTBS) at the Oral Cancer Research and Coordinating Centre (OCRCC). High quality poly A+ RNA was extracted from macrodissected tumour and normal epithelial tissue to obtain $>70 \%$. Validation of second generation sequencing was done using commercial and custom microarrays. Principle component analysis (PCA) was applied to the sequenced generated data. Results and discussion: PCA showed distinct clusters separating groups of current and former smokers. The former smoker who ceased smoking >25 years clustered closely with normal non-smoker suggesting expression levels of some of the genes related to tobacco smoking could return to levels similar to never smokers upon cessation of smoking. When comparing differential gene expression between tumor in former and current smokers, ACTC1, MYH2, DES, MYBPH, MYLPF were the top 5 most down-regulated genes. Meanwhile, CYP2W1, FAIM2, OLFML1, KRT13 were found to be up-regulated when comparing differential gene expression between these groups (fold change $>8$ ). Despite prolonged smoking cessation, some gene expression could appear to be permanently altered and these irreversible changes may account for oral cancer risk despite smoking cessation. Conclusion: These findings illustrate the potential for next generation sequencing to provide insights into the unique gene expression profiles associated with risk habits which will be useful in developing biomarkers for prognostic and therapeutic applications in the future.

\begin{tabular}{|c|l|}
\hline Author & $\begin{array}{l}\text { Zain, R. B; Karen-Ng, L. P.; Cheong, S. C. ; Anwar, A. ; Mustaffa, } \\
\text { W. M. W. Prepagaran, N. Zaini, Z. Merican, A. F. Abraham, M. T. } \\
\text { Tay, K. K. Rahman, Z. A. A. Jallaludin, A. }\end{array}$ \\
\hline Source & Oral Oncology \\
\hline ISSN & $1368-8375$ \\
\hline DOI & $10.1016 /$ j.oraloncology.2011.06.169 \\
\hline Volume & 47 \\
\hline Page & S48-S48 \\
\hline Year & 2011 \\
\hline
\end{tabular}


Keyword:

Oral squamous cell carcinoma, OSCC, lichenoid lesions, lichen planus, oral cancer, oral tumours, pemphigus, traumatic eosinophilic granuloma, aphthous ulcers, oral mucosal lesions, betel chewers mucosa, betel quid related lesions, betel quid, areca quid, tobacco quid, oral cancer screening, training and calibration, early detection, oral cancer awareness, biobanking, tissue bank, databank, oral cancer, tissue bank, research credibility, research ethics.

Please Cite As:

ZAIN, R. B., KAREN-NG, L. P., CHEONG, S. C., ANWAR, A., MUSTAFFA, W. M. W., PREPAGARAN, N., ZAINI, Z., MERICAN, A. F., ABRAHAM, M. T., TAY, K. K., RAHMAN, Z. A. A. \& JALLALUDIN, A. 2011. Effects of smoking on oral cancer transcriptome. Oral Oncology, 47, S48-S48.

URL:

- http://www.sciencedirect.com/science/article/pii/S1368837511003757

- http://apps.webofknowledge.com Search via Web of Science Accession No : 000292815100137 